ORIGINAL PAPER

\title{
Age- AND DEgENERATION-RELATED VARIATIONS IN CELL DENSITY AND GLYCOSAMINOGLYCAN CONTENT IN THE HUMAN CERVICAL INTERVERTEBRAL DISC AND ITS ENDPLATES
}

\author{
Krzysztof A. Tomaszewski ${ }^{1}$, Jerzy A. Walocha ${ }^{1}$, Ewa Mizia ${ }^{1}$, Tomasz Gladysz ${ }^{1,2}$, \\ Roman GŁowacki ${ }^{3}$, Romana Tomaszewska ${ }^{4}$
}

\begin{abstract}
${ }^{1}$ Department of Anatomy, Jagiellonian University Medical College, Krakow, Poland ${ }^{2}$ Department of Oral Surgery, Institute of Dentistry, Jagiellonian University Medical College, Krakow, Poland ${ }^{3}$ Department of Otorhinolaryngology, Ludwik Rydygier Specialist Hospital, Krakow, Poland

${ }^{4}$ Department of Pathology, Jagiellonian University Medical College, Krakow, Poland
\end{abstract}

\begin{abstract}
The first aim of this study was to quantify cell density in cervical intervertebral discs (IVDs) and endplates of varying age and degeneration grade. The second aim was to analyze glycosaminoglycan (GAG) content in cervical IVDs and their endplates. Sixty cervical IVDs were excised from 30 human cadavers, not later than 24 hours post-mortem. Each sample underwent sectioning. Half of each sample underwent GAG content analysis using the dimethylmethylene blue binding assay. The other half underwent histological processing, histological degeneration grading, and cell density assessment using the Abercrombie method.

The nucleus pulposus (NP) ( $4218 \pm 417$ cells $\left./ \mathrm{mm}^{3}\right)$ had significantly higher cell density than the anterior annulus fibrosus (AF) $\left(3283 \pm 438\right.$ cells $\left./ \mathrm{mm}^{3} ; \mathrm{p}<0.0001\right)$, and similar cell density $\left(4464 \pm 551\right.$ cells $\left./ \mathrm{mm}^{3} ; \mathrm{p}=0.36\right)$ to the posterior AF. Cell density was similar throughout the different regions of the endplate. The NP $(619 \pm 178$ $\mu \mathrm{g} / \mathrm{mg}$ dry weight) had a significantly higher GAG content than both the anterior $(428 \pm 199 \mu \mathrm{g} / \mathrm{mg}$ dry weight; $\mathrm{p}<0.0001)$ and posterior $\mathrm{AF}(524 \pm 218 \mu \mathrm{g} / \mathrm{mg}$ dry weight; $\mathrm{p}<0.0001)$.

In conclusion, this study introduces detailed 3D maps of cervical IVD and endplate cell density and GAG content. Furthermore, it shows that cervical IVDs and their endplates only slightly differ, in terms of cell density and GAG content, from lumbar IVDs.
\end{abstract}

Key words: cell density, degeneration, endplate, glycosaminoglycans, intervertebral disc.

\section{Introduction}

The intervertebral discs (IVD) are cylindrical, fibrocartilaginous structures responsible for articulation between vertebral bodies. They allow for flexion, extension, and rotation of the otherwise rigid anterior portion of the vertebral column [1]. Macroscopically the IVD can be divided into an outer annulus fibrosus (AF) which surrounds a centrally located nucleus pulposus (NP). This "two-compartment" structure allows the IVD to successfully function as a load-bearing unit [2]. The IVD is bordered, from the cranial and caudal sides, by the endplates, which possess an osseous as well as a hyaline cartilage component [3]. One of their main roles is to prevent the 
highly hydrated NP from bulging into the adjacent vertebrae.

With ageing the IVD undergoes changes, in terms of its extracellular matrix composition, as well as cell density and character $[4,5,6]$. From early childhood, the blood supply to the IVD and the endplates decreases [7], together with cell density [8], leading to an increased incidence of structural defects. Since IVD cells are responsible for matrix formation and maintenance, their proper quantity, quality, and distribution in the regional compartments of the IVD may be crucial in preventing degeneration. However, changes in cell density with ageing thus far have only been shown in lumbar IVDs [8, 9]. Recent years have brought about new treatment modalities for disc degenerative disease (DDD) - these include autologous or allogeneic cell transplantation $[8,10,11]$, mesenchymal stem cell transfer [12], and genetically modified cell transformation. However, for these treatments to be effective one would have to know the cell density baseline values which can be expected when treating individuals of a certain age and level of IVD degeneration. The current literature lacks information on cell density age- and degeneration-related changes in human cervical IVDs and endplates. As a result the number of cells implanted into IVDs, in various animal experiments, varies significantly $[10$, $11,12]$. This emphasizes the need to establish cell density values in regard to patient age and IVD degeneration. Such knowledge would allow future cellbased therapies to deliver adequate numbers of cells with each treatment.

The correct spatial distribution of proteoglycans (with glycosaminoglycan chains - GAG) in the IVD is crucial for the discs' physiological swelling behaviors, streaming potential, and compressive properties [13]. During IVD degeneration, proteolytic fragmentation of large and small proteoglycans may induce or inhibit essential inflammatory response pathways, altering the ability of the extracellular matrix to maintain its structural integrity [14, 15]. Loss of proteoglycans in the NP is a clear sign of early IVD degeneration [16]. Thus far, several studies have investigated the distribution of sulfated GAGs in lumbar IVDs, in the sagittal [17] as well as coronal and axial [18] directions. However, no such study has been performed in cervical IVDs. As IVD degeneration is driven partially by aging [15], it is not easy to differentiate changes that are a consequence of aging itself from those that develop because of tissue degeneration and the accompanying repair process. Additional research is needed to determine how age and degeneration influence IVD and endplate extracellular matrix composition.

The first aim of this study was to quantify cell density in cervical IVDs and endplates of varying age and degeneration grade to produce cell density maps, which would provide a knowledge base for future cell-based therapies for cervical DDD. As IVD cells are directly responsible for proteoglycan production, the second aim of the study was to analyze GAG content in cervical IVDs and their endplates. This part of the study aimed at providing additional insight into IVD and endplate physiology and pathology, and was meant to supply data for future computer modeling of IVD behavior.

\section{Material and methods}

\section{Material acquisition}

Sixty cervical IVDs were excised from 30 human cadavers (at the Department of Forensic Medicine, Jagiellonian University Medical College), using the anterior approach, not later than 24 hours post-mortem [19]. The material was excised in one block comprising vertebral bodies, IVDs, endplates and blood vessels supplying these structure, wrapped in saline-soaked gauze, vacuum-sealed to prevent dehydration, and kept at $4^{\circ} \mathrm{C}$ for transport, until further processing. Excision started at the level of the lower half of the C4 vertebra and ended at the level of the upper half of the C6 (Fig. 1).

The study inclusion criterion was the ability to excise a section of the anterior spinal column (from the lower half of the $\mathrm{C} 4$ vertebra to the upper half of the C6), with the anterior and posterior longitudinal ligaments and blood vessels supplying the vertebrae. Study exclusion criteria were: (1) injury to the cervical spine, preventing excision of the required section; (2) previous cervical spine surgery; (3) receiving chemotherapy in the last 12 months; (4) previous radiation therapy to the perispinal region; (5) long-standing paralysis (6 or more months); (6) ankylosing spondylitis.

\section{Material processing}

On the same day each sample was unpacked from the vacuum-sealed container. Intervertebral discs were isolated by removing extraneous soft tissue and adjacent vertebrae using a scalpel/microscalpel under an operating microscope (OPMI Pico, Zeiss). Special attention was paid not to remove the cartilaginous endplates (both cranial and caudal), and leave them intact with the IVDs. To assure this a thin layer of subchondral bone was left attached to the IVD.

Each IVD was then dissected, using a custom made $3 \mathrm{~mm} \times 3 \mathrm{~mm}$ die-cutter, in order to obtain an array of square samples spanning the sagittal direction from anterior to posterior (4-7 sections, depending on IVD size) and also spanning the coronal direction from left lateral to central to right lateral locations (5-8 sections) [18]. Additionally, IVD sections from 5 different regions (anterior, posterior, 


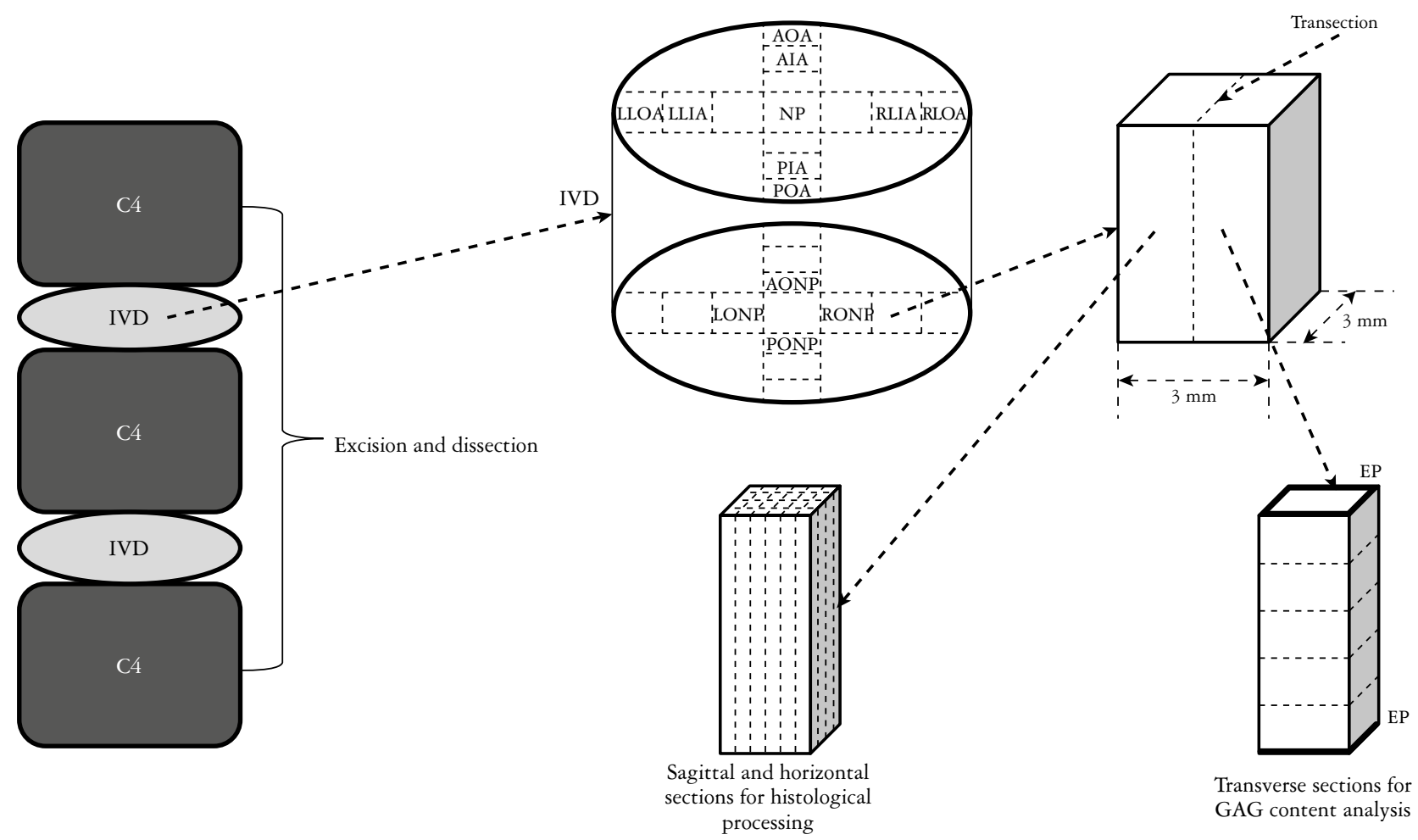

C4-C6 - fourth to sixth cervical vertebrae; IVD - intervertebral disc; AOA - anterior outer annulus; AIA - anterior inner annulus; PIA - posterior inner annulus; $P O A$ - posterior outer annulus; $L L O A$ - left lateral outer annulus; LLIA - left lateral inner annulus; RLIA - right lateral inner annulus; RLOA - right lateral outer annulus; NP - nucleus pulposus; AONP - anterior outer nucleus pulposus; PONP - posterior outer nucleus pulposus; LONP - left outer nucleus pulposus; RONP - right outer nucleus pulposus; EP - endplate; GAG-glycosaminoglycan

Fig. 1. Study material acquisition and processing

lateral, and nucleus pulposus) were further divided - first into 2 sections (sagittal plane). Then, one of the two sections was further divided into 5 sections to evaluate the distribution of GAG content in the axial direction. Material acquisition and processing are depicted in Fig. 1.

\section{Macroscopic degeneration grading and tissue processing}

During die-cutting, each IVD was sectioned at the midsagittal plane, which allowed for macroscopic IVD degeneration scoring according to Thompson's 5 -grade classification [20]. Grade 1 corresponds to a healthy IVD, while grade 5 represents the most severely degenerated IVD. Each specimen was assessed by two of the authors, and the grade was averaged. Next, the samples chosen for further histological analysis (Fig. 1) were placed in a $10 \%$ solution of formaldehyde ( $\mathrm{pH}$ 7.4) for a minimum of 14 days for fixing. The samples chosen for GAG content analysis were immediately processed (see below).

\section{Macroscopic degeneration grading and histological processing}

Microscopic IVD and endplate (both cranial and caudal) degeneration was assessed using the histologic degeneration score (HDS) [7]. In brief, the HDS semiquantitatively scores cellular organization (cell proliferation), cleft/tear formations, granular changes, and mucoid degeneration in anterior/posterior annulus fibrosus (AF) and nucleus pulposus (NP) regions. It produces a summary score separately for the $\mathrm{AF} / \mathrm{NP}(0-22)$ and the endplate (0-18).

The NP/AF scores were grouped as follows [8]: group I: 0-2; group II: 3-7; group III: 8-12; group IV: 13-17; group V: 18-22 (tissue defects, scar). The EP scores were grouped as follows: group I: 0-2; group II: 3-5; group III: 6-9; group IV: 10-12; group V: 13-18 (tissue defects, scar, ossification). Group V did not encompass normal disc tissue and thus was not included in the calculation of cell density.

Tissue samples were acquired from the midsagittal and midcoronal planes of each of the IVD regions (Fig. 1). Fixed samples were decalcified, dehydrated, embedded in paraffin, sectioned midsagittally at $4 \mu \mathrm{m}$, and stained with hematoxylin and eosin (HE), Masson-Goldner trichrome and alcian blue-PAS (Department of Pathology, Jagiellonian University Medical College). Each sample was assessed and scored, using light microscopy (Nikon Eclipse 80i), by two observers, and the final score per sample was averaged [21].

Additional horizontal sections, of each sample, were prepared in the same manner with $\mathrm{H} \& \mathrm{E}$ staining to determine the calculated cell density using the 
Abercrombie method [8, 22]. Each sample was photographed and analyzed using Java ImageJ (developed by Wayne Rasband) [23].

The degree of endplate calcification was analyzed as the percentage of calcified tissue (red on Masson-Goldner trichrome staining) to the non-calcified part. The fact of endplate calcification was verified on corresponding HE stained samples. The percentage of calcification was averaged for all examined endplate regions.

\section{Cell density analysis and cell nucleus correction factor}

A morphometric analysis was performed to determine the cell number per analyzed region (Fig. 1) of IVD and EP, using sagittal slices. All measurements were performed using a light microscope (Nikon Eclipse $80 \mathrm{i})$ with an ocular grid $(10 \times 10$ fields $)$. The number of cell nuclei was counted from the superior to the inferior part of the section (magnification $400 \times$ ) [8]. Twenty consecutive grids in the anterior-posterior dimension and a variable number of grids (depending on the thickness of the sample) in the superior-inferior direction were analyzed. Different cell types were distinguished based on their morphology.

As the nuclei of IVD cells are usually larger than $5 \mu \mathrm{m}$, they may appear in more than 1 section, which results in an overestimation of the total cell number. Abercrombie [22] developed a correction factor to determine cell density $(\mathrm{T})$ including the number of nuclei $(\mathrm{N})$ per area $\left(\mathrm{N} / \mathrm{mm}^{2}\right)$, the section thickness (S), and the diameter of the cell nucleus (D). Based on this method we included a correction factor of 240 to obtain the cell number per $\mathrm{mm}^{3}$. The number of cell nuclei was counted using ImageJ software.

\section{Measuring GAG content}

After dissection (Fig. 1) each sample was placed in pre-weighed vials, weighed, and lyophilized to obtain dry weights using a balance with $\pm 0.01 \mathrm{mg}$ resolution (DV215CD, Ohaus).

Dry tissue was solubilized using proteinase $\mathrm{K}$ (0.5 $\mathrm{mg} / \mathrm{ml}$, Sigma Aldrich) and assayed for GAG content using the dimethylmethylene blue (DMMB) dye binding assay as previously described for disc tissue [16]. The GAG content was calculated based on a standard curve using an aqueous solution of chondroitin sulfate sodium salt from shark cartilage (chondroitin 6-sulfate, Sigma Aldrich, cat. no. C4384). All GAG content measurements were performed in duplicate and expressed as $\mu \mathrm{g} / \mathrm{mg}$ of dry tissue.

\section{Statistical analysis}

Statistical analysis was conducted using Statistica 10.0 (StatSoft). Elements of descriptive statistics were used (mean, standard deviation percentage dis- tribution). Differences between groups were tested with the paired Student's t test. To assess the correlation between scores, Pearson's correlation was used. Inter-rater reliability of the histologic assessment of cell density and the HDS was assessed using the intraclass correlation coefficient (ICC). Statistical significance was set at $\mathrm{p}<0.05$.

\section{Ethics}

The research protocol was approved by the Jagiellonian University Medical College Ethics Committee (registry number KBET/319/B/2012). The study was performed in accordance with the ethical standards laid down in the 1964 Declaration of Helsinki and its later amendments. The specimen excision method was chosen so as not to destabilize the cadaver's spinal column.

\section{Results}

The study group comprised 30 female and 30 male IVDs. The mean age $\pm \mathrm{SD}$ of the specimens was $51.4 \pm 19.5$. The basic characteristics of the study group are presented in Table I.

\section{Interobserver reliability}

The interclass correlation coefficient for the assessment of cell density from two randomly selected midsagittal sections per Thompson degeneration grade with a total of 100 regions of interest (ROIs) displayed a very high reliability coefficient $\alpha$ of 0.92 .

\section{Cell density in the intervertebral disc}

Cell density per chosen IVD region in relation to the HDS grade is presented in Table II. The average cell number differed significantly between the anterior $\left(3283 \pm 438 \mathrm{cells} / \mathrm{mm}^{3}\right)$ and posterior $(4464 \pm 551$ cells $\left./ \mathrm{mm}^{3}\right)$ AF $(\mathrm{p}<0.0001)$. The NP $(4218 \pm 417$ cells $/ \mathrm{mm}^{3}$ ) had significantly higher cell density than the anterior $\mathrm{AF}(\mathrm{p}<0.0001)$ and similar cell density $(p=0.36)$ to the posterior AF. Comparison by side of AF showed no difference $(\mathrm{p}=0.51)$ between the left $\left(4875 \pm 378\right.$ cells $\left./ \mathrm{mm}^{3}\right)$ and right $(4735 \pm 385$ cells/ $\mathrm{mm}^{3}$ ) sides in terms of cell density.

The HDS negatively correlated with cell density in all of the IVD regions $(\mathrm{r}=-0.31-(-0.55) ; \mathrm{p}<$ $0.003)$. This correlation was strongest for the NP.

Age significantly negatively correlated with cell density only in the anterior $\mathrm{AF}(\mathrm{r}=-0.28 ; \mathrm{p}=0.009)$ and the NP $(r=-0.37 ; p<0.0001)$. Maps of average IVD cell density for typical 20-30, 40-50, 60-70, and 80-90 years old are shown in Fig. 2A.

There were no significant differences between sexes in terms of IVD cell density with the exception of the NP (males $3162 \pm 886$ cells $/ \mathrm{mm}^{3}$ vs. females $5069 \pm 5269$ cells $\left./ \mathrm{mm}^{3} ; \mathrm{p}<0.001\right)$. 
Table I. Basic characteristics of the study group

\begin{tabular}{|c|c|c|c|c|}
\hline PARAmeter & $\begin{array}{c}\text { Female } \\
(\mathrm{N}=30)\end{array}$ & $\begin{array}{c}\text { Male } \\
(\mathrm{N}=30)\end{array}$ & $\begin{array}{c}\text { Total } \\
(\mathrm{N}=60)\end{array}$ & P-VALUE ${ }^{1}$ \\
\hline \multirow[t]{2}{*}{ Age (SD) } & 52.8 & 50.0 & 51.4 & \multirow[t]{2}{*}{0.57} \\
\hline & $(19.8)$ & $(19.4)$ & $(19.5)$ & \\
\hline IVD degeneration & 2.6 & 3.2 & 2.9 & \multirow[t]{2}{*}{0.08} \\
\hline Thompson classification (SD) & $(1.3)$ & $(1.3)$ & $(1.3)$ & \\
\hline IVD degeneration & 12.0 & 14.3 & 13.1 & \multirow[t]{2}{*}{0.13} \\
\hline HDS score $(0-22)(\mathrm{SD})$ & $(6.1)$ & $(5.3)$ & $(5.8)$ & \\
\hline Endplate degeneration & 8.9 & 11.5 & 10.2 & 0.06 \\
\hline HDS score $(0-18)(\mathrm{SD})$ & $(5.3)$ & $(4.8)$ & $(5.2)$ & \\
\hline \multirow[t]{2}{*}{ Endplate calcification $[\%](\mathrm{SD})$} & 28.4 & 44.1 & 36.2 & \multirow[t]{2}{*}{0.02} \\
\hline & $(25.1)$ & $(26.0)$ & $(26.5)$ & \\
\hline \multicolumn{5}{|c|}{ IVD degeneration } \\
\hline \multicolumn{5}{|c|}{ Thompson classification vs. degree of endplate calcification [\%] (SD) } \\
\hline \multirow[t]{2}{*}{ Grade I } & 6.2 & 6.7 & 6.3 & \multirow[t]{2}{*}{0.31} \\
\hline & $(2.6)$ & $(0.6)$ & $(2.1)$ & \\
\hline \multirow[t]{2}{*}{ Grade II } & 13.2 & 17.7 & 14.8 & \multirow[t]{2}{*}{$<0.0001$} \\
\hline & $(2.8)$ & $(1.9)$ & $(3.3)$ & \\
\hline \multirow[t]{2}{*}{ Grade III } & 29.6 & 37.1 & 34.4 & \multirow[t]{2}{*}{0.0006} \\
\hline & $(8.7)$ & $(7.3)$ & $(8.4)$ & \\
\hline \multirow[t]{2}{*}{ Grade IV } & 53.3 & 61.6 & 57.9 & \multirow[t]{2}{*}{$<0.0001$} \\
\hline & $(6.9)$ & $(4.8)$ & $(7.0)$ & \\
\hline \multirow[t]{2}{*}{ Grade V } & 77.3 & 79.1 & 78.5 & \multirow[t]{2}{*}{0.28} \\
\hline & $(8.5)$ & $(2.8)$ & $(5.2)$ & \\
\hline
\end{tabular}

${ }^{1}$ - for differences between females and males

$S D$ - standard deviation; IVD - intervertebral disc; HDS - bistologic degeneration score

\section{Cell density in the endplate}

Differences in cell density between the cranial and caudal endplates were not statistically significant $(p>0.05)$; thus the results were presented as an average value of cranial and caudal endplate cellularity.

Cell density per chosen endplate region in relation to the HDS grade is displayed in Table III. When comparing the average cell number between the endplate region underlying the anterior (18 $624 \pm 1774$ cells/ $\left.\mathrm{mm}^{3}\right)$ and posterior $\left(18829 \pm 1569\right.$ cells $\left./ \mathrm{mm}^{3}\right) \mathrm{AF}$ no significant difference was noted $(\mathrm{p}=0.89)$. The endplate region underlying the NP (19 $744 \pm 1698$ cells $/ \mathrm{mm}^{3}$ ) had similar cell density when compared to the anterior $(\mathrm{p}=0.39)$ and posterior $(\mathrm{p}=0.40)$ $\mathrm{AF}$ regions. Comparison by side of endplate region underlying the AF showed no difference $(\mathrm{p}=0.93)$ between the left $\left(18463 \pm 1543\right.$ cells $\left./ \mathrm{mm}^{3}\right)$ and right $\left(18540 \pm 1622\right.$ cells $\left./ \mathrm{mm}^{3}\right)$ sides in terms of cell density.

The HDS significantly negatively correlated with cell density in all of the endplate regions $(r=-0.72$ -
$(-0.77) ; \mathrm{p}<0.0001)$. This correlation was strongest for the region underlying the posterior AF.

Age significantly negatively correlated with cell density in all of the endplate regions $(\mathrm{r}=-0.44-(-$ $0.53) ; \mathrm{p}<0.0001$ ), and was strongest for the region underlying the anterior $\mathrm{AF}(\mathrm{r}=-0.53 ; \mathrm{p}<0.0001)$. Maps of average endplate cell density for typical 20$30,40-50,60-70$, and 80-90 years old are shown in Fig. 2B.

Endplate calcification strongly negatively correlated with cell density in the endplate $(\mathrm{r}=-0.51$ $(-0.56) ; \mathrm{p}<0.0001)$.

There were no significant differences between sexes in terms of endplate cell density for all analyzed regions $(\mathrm{p}>0.05)$.

\section{Glycosaminoglycan content in the intervertebral disc}

Glycosaminoglycan content per chosen IVD region in relation to the HDS grade is presented in Table IV. When comparing the average GAG content between the anterior ( $428 \pm 199 \mu \mathrm{g} / \mathrm{mg}$ dry weight) and pos- 
Table II. Cell density per intervertebral disc region in relation to the histologic grade of disc degeneration

\begin{tabular}{lclll}
\hline $\begin{array}{l}\text { IVD REGION } \\
{\left[\text { CELL/MM }{ }^{3}\right]}\end{array}$ & HDS I & HDS II & HDS III & HDS IV \\
\hline AOA & $22124(2333)$ & $2412(192)$ & $1864(211)$ & $2586(179)$ \\
\hline AIA & $22549(2058)$ & $2484(188)$ & $2225(201)$ & $2715(124)$ \\
\hline AONP & $22182(2035)$ & $3790(727)$ & $4007(914)$ & $2624(273)$ \\
\hline NP & $21462(3577)$ & $3521(715)$ & $4481(564)$ & $2599(378)$ \\
\hline PONP & $24523(962)$ & $3850(824)$ & $3654(1141)$ & $2805(326)$ \\
\hline PIA & $28662(1061)$ & $2891(931)$ & $2190(338)$ & $5139(798)$ \\
\hline POA & $26623(779)$ & $2391(595)$ & $1908(359)$ & $4454(669)$ \\
\hline LLOA & $19184(906)$ & $2821(463)$ & $2255(303)$ & $5273(1063)$ \\
\hline LLIA & $20759(401)$ & $4914(674)$ & $4106(473)$ & $4930(1576)$ \\
\hline LONP & $21124(1894)$ & $4364(752)$ & $3638(827)$ & $2761(247)$ \\
\hline RONP & $21199(2741)$ & $3718(887)$ & $3667(1160)$ & $2598(261)$ \\
\hline RLIA & $20663(411)$ & $4798(647)$ & $3744(522)$ & $4699(1571)$ \\
\hline RLOA & $19868(840)$ & $3001(668)$ & $2163(294)$ & $5105(1007)$ \\
\hline $\begin{array}{l}\text { Anterior AF } \\
\text { averaged) }\end{array}$ & $22337(1813)$ & $2448(188)$ & $2045(273)$ & $2651(165)$ \\
\hline NP (averaged) & $22098(2238)$ & $3849(799)$ & $3889(978)$ & $2677(307)$ \\
\hline $\begin{array}{l}\text { Posterior AF } \\
\text { averaged) }\end{array}$ & $27642(1401)$ & $2641(801)$ & $2049(371)$ & $4797(805)$ \\
\hline Vahe in brkes $)$ & & & \\
\hline
\end{tabular}

Values in brackets represent standard deviations.

$H D S$ - bistologic degeneration score; IVD - intervertebral disc; EP - endplate; AOA - anterior outer annulus; AIA - anterior inner annulus; PIA - posterior inner annulus; POA - posterior outer annulus; LLOA - left lateral outer annulus; LLIA - left lateral inner annulus; RLIA - right lateral inner annulus; RLOA - right lateral outer annulus; NP - nucleus pulposus; AONP - anterior outer nucleus pulposus; PONP - posterior outer nucleus pulposus; LONP - left outer nucleus pulposus; RONP - right outer nucleus pulposus; AF - annulus fibrosus.

terior $(524 \pm 218 \mu \mathrm{g} / \mathrm{mg}$ dry weight) AF a significant difference was noted ( $\mathrm{p}<0.001)$. The NP $(619$ $\pm 178 \mu \mathrm{g} / \mathrm{mg}$ dry weight) had a significantly higher GAG content than both the anterior $(\mathrm{p}<0.0001)$ and posterior $\mathrm{AF}(\mathrm{p}<0.0001)$. Comparison by side of AF showed no difference ( $\mathrm{p}=0.63$ ) between the left (479 $\pm 201 \mu \mathrm{g} / \mathrm{mg}$ dry weight) and right (470 \pm 192 $\mu \mathrm{g} / \mathrm{mg}$ dry weight) sides in terms of GAG content.

The HDS negatively correlated with GAG content in all of the IVD regions $(r=-0.47-(-0.71)$; $\mathrm{p}<0.0001)$. This correlation was strongest for the NP.

Age significantly negatively correlated with GAG content in all of the IVD regions ( $r=-0.60-(-0.90)$; $\mathrm{p}<0.0001)$, and was strongest for the region of the NP. Maps of average IVD GAG content for typical 20-30, 40-50, 60-70, and 80-90 years old are shown in Fig. 3A.

There were no significant differences between sexes in terms of GAG content in any of the IVD regions $(\mathrm{p}>0.05)$.

\section{Glycosaminoglycan content in the endplate}

Differences in GAG content between the cranial and caudal endplates were not statistically significant $(\mathrm{p}>0.05)$; thus the results were presented as an average value of cranial and caudal endplate GAG content.

Glycosaminoglycan content per chosen endplate region in relation to the HDS grade is presented in Table V. When comparing the average GAG content between the endplate region underlying the anterior (169 $\pm 52 \mu \mathrm{g} / \mathrm{mg}$ dry weight) and posterior (192 $\pm 57 \mu \mathrm{g} / \mathrm{mg}$ dry weight) AF a significant difference was noted ( $p<0.0001)$. The endplate region underlying the NP $(209 \pm 58 \mu \mathrm{g} / \mathrm{mg}$ dry weight $)$ had significantly higher GAG content than the anterior $(\mathrm{p}<0.0001)$ and posterior $(\mathrm{p}<0.0001)$ AF regions. Comparison by side of endplate region underlying the AF showed no difference $(\mathrm{p}=0.84)$ between the left $\left(199 \pm 56\right.$ cells $\left./ \mathrm{mm}^{3}\right)$ and right $(200 \pm 57 \mu \mathrm{g} / \mathrm{mg}$ dry weight) sides in terms of GAG content.

The HDS significantly negatively correlated with GAG content in all of the endplate regions ( $\mathrm{r}=$ $=-0.57-(-0.64) ; \mathrm{p}<0.0001)$. The correlation was strongest for the region underlying the NP.

Age significantly negatively correlated with GAG content in all of the endplate regions $(r=-0.82-$ $(-0.88) ; \mathrm{p}<0.0001)$, and was strongest for the regions underlying the left and right AF. Maps of aver- 

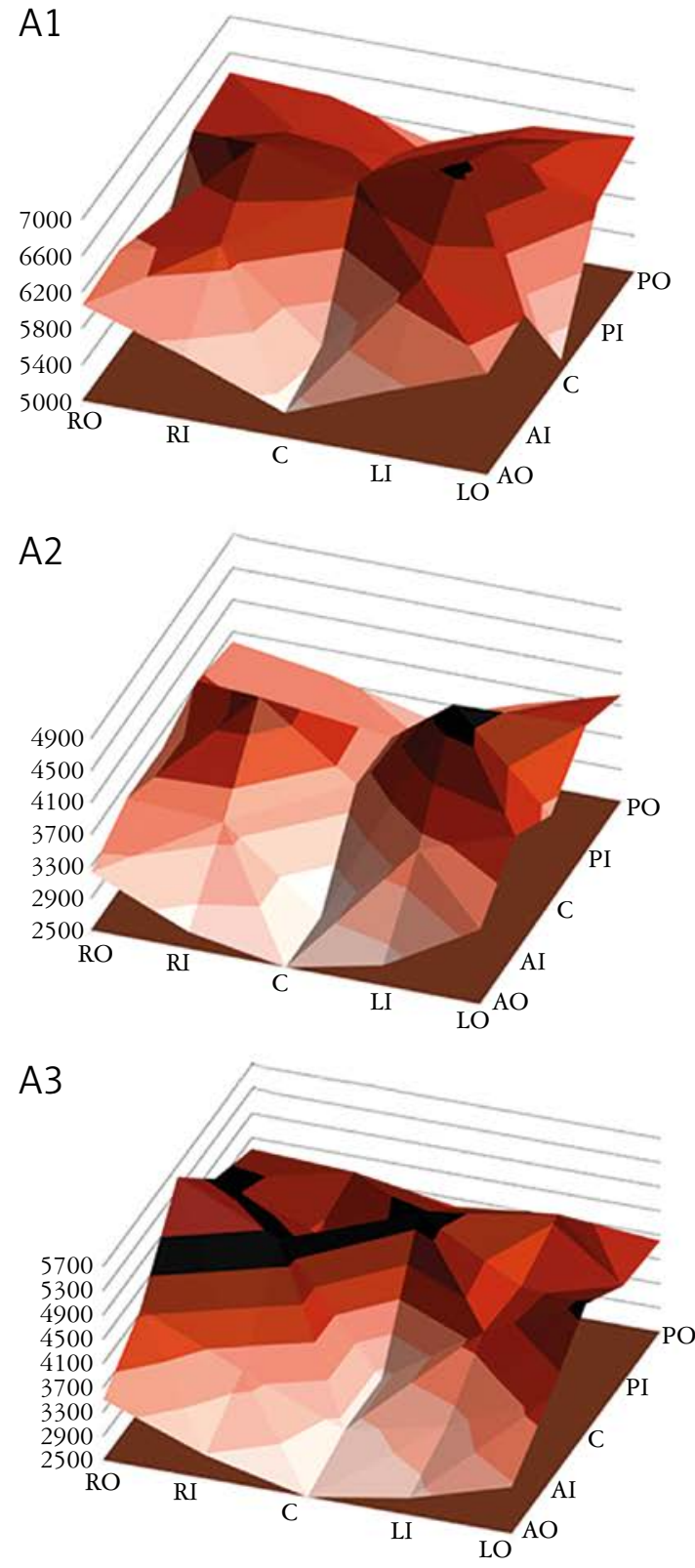

A4
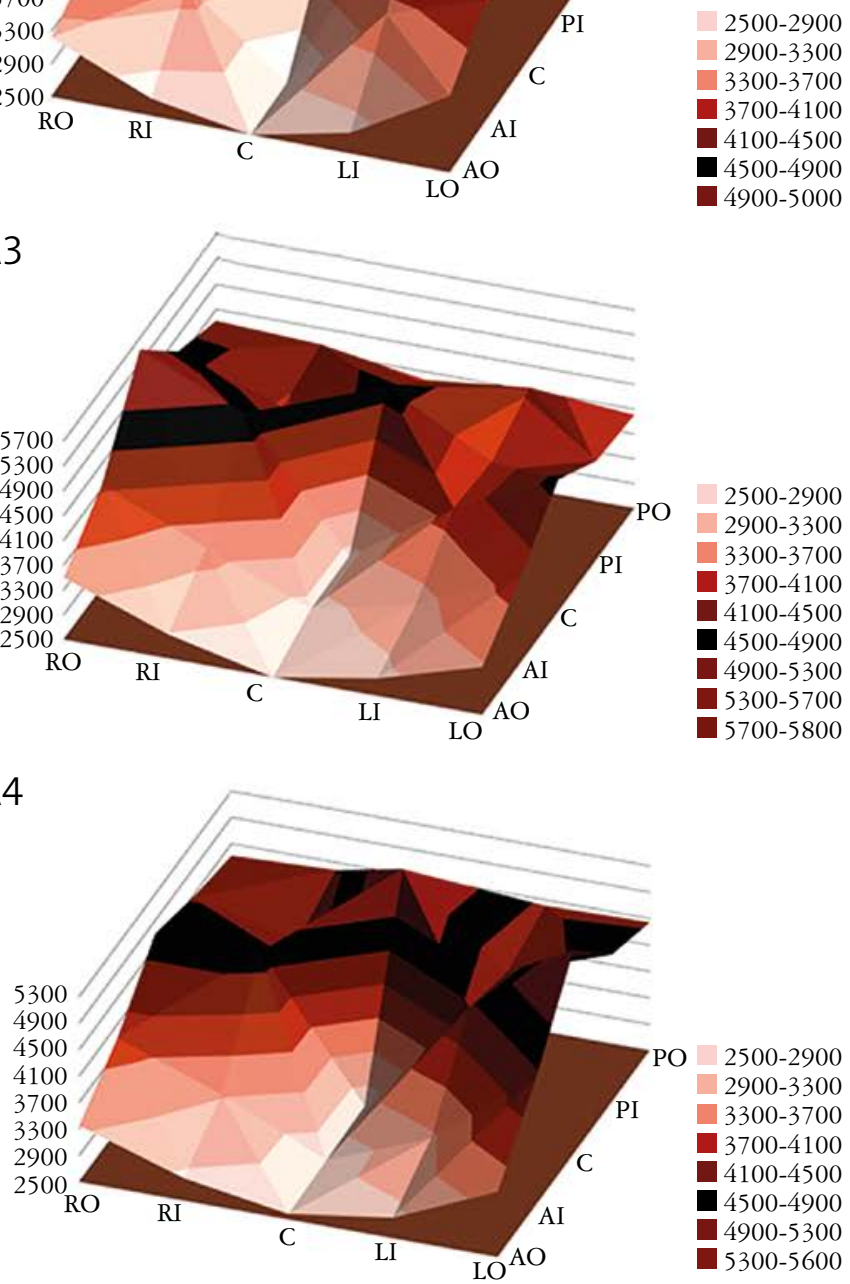

2500-2900 2900-3300 3300-3700

- 3700-4100

- 4100-4500

- 4500-4900

4900-5300

- 5300-5700

- 5700-5800

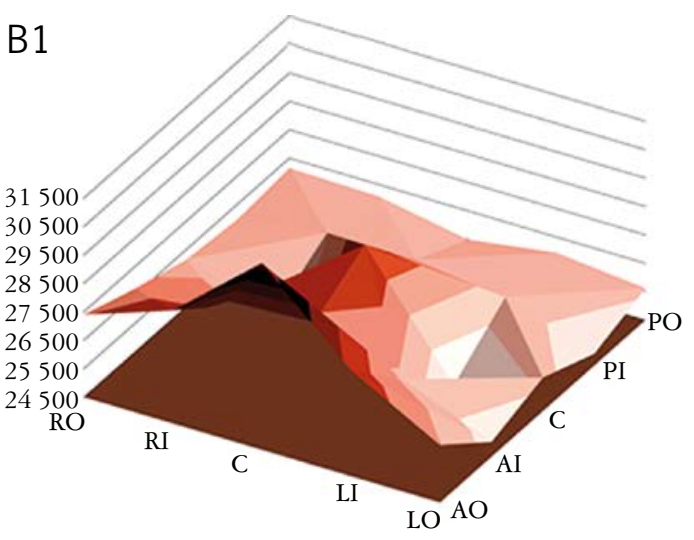

$24500-25500$ 25 500-26 500 $26500-27500$ - 27 500-27 500 - 28 500-29 500 29 500-30500

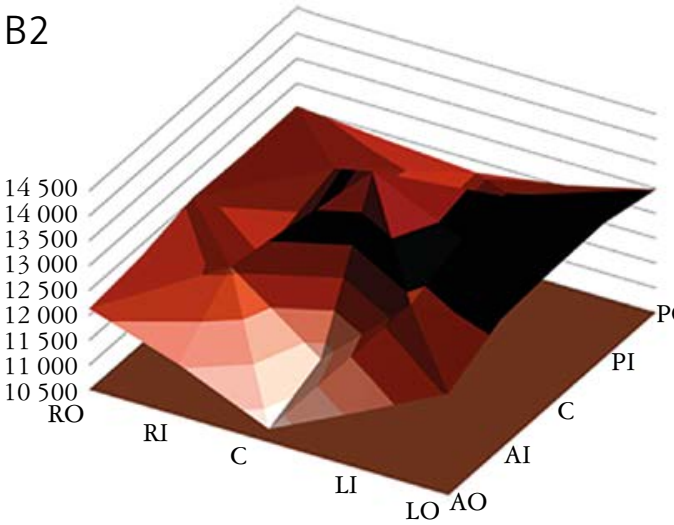

-30 500-31500

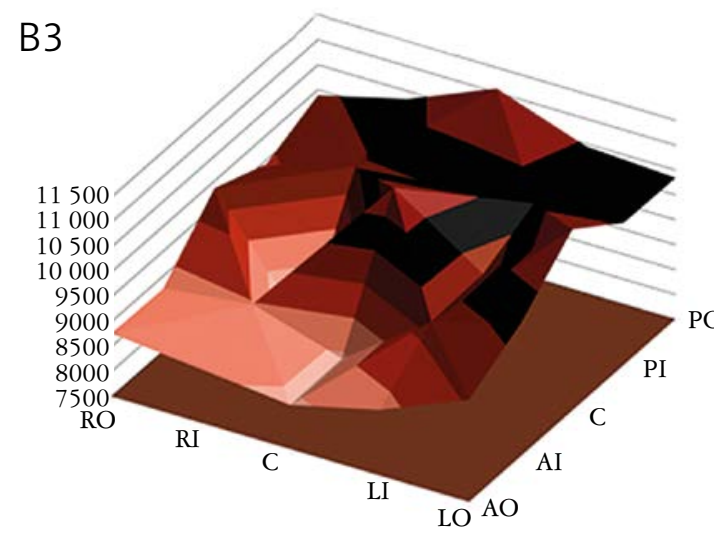

10 500-11000 - 11 000-11 500 $11500-12000$ 12 000-12 500 - 12 500-13000 - 13 000-13500 13 500-14 000 14 000-14 500

B4

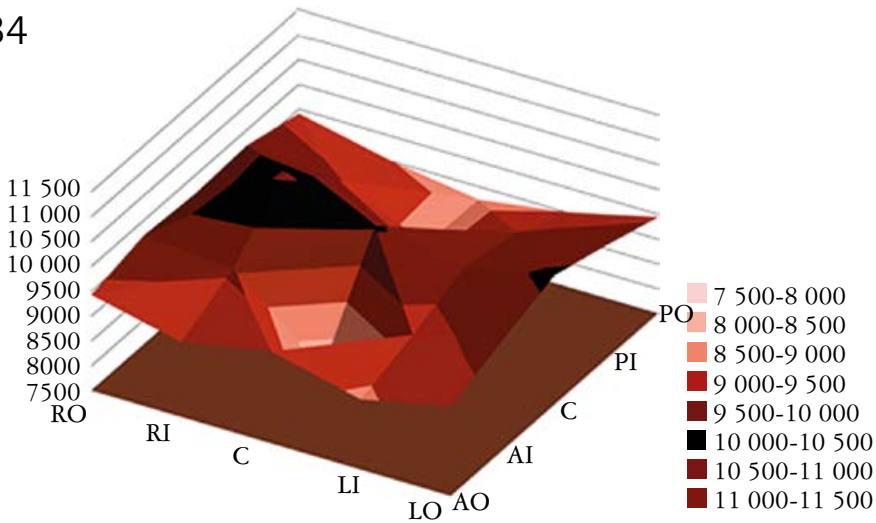

Please note the change in scale between different maps. Values are expressed as number of cells per $\mathrm{mm}^{3}$.

$A 1$ - intervertebral disc (20-30 years old); B1 - endplate (20-30 years old); A2 - intervertebral disc (40-50 years old); B2 - endplate (40-50 years old); A3 - intervertebral disc (60-70 years old); B3 - endplate (60-70 years old); A4 - intervertebral disc (80-90 years old); B5 - endplate (80-90 years old). $C$ - center; $L I$ - left inner; $L O$ - left outer; $R I$ - right inner; $R O$ - right outer; $A O$ - anterior outer; AI - anterior inner; $P I$ - posterior inner; PO - posterior outer.

Fig. 2. Three-dimensional maps of average intervertebral disc (A) and endplate (B) cell density shown for different age groups 
Table III. Cell density per endplate region in relation to the histologic grade of endplate degeneration

\begin{tabular}{lcccc}
\hline $\left.\begin{array}{l}\text { EP REGION } \\
{[\text { CELL/MM }}\end{array}\right]$ & HDS I & HDS II & HDS III & HDS IV \\
\hline AOA & $37252(3408)$ & $45174(17896)$ & $8925(1438)$ & $9538(884)$ \\
\hline AIA & $35855(4445)$ & $40046(9071)$ & $8579(1763)$ & $9458(1070)$ \\
\hline AONP & $36033(3946)$ & $50041(13619)$ & $8870(1317)$ & $13207(2372)$ \\
\hline NP & $46639(12563)$ & $20779(5995)$ & $12135(3084)$ & $12703(1839)$ \\
\hline PONP & $45596(3108)$ & $39961(13779)$ & $11821(2003)$ & $12551(1712)$ \\
\hline PIA & $40745(12186)$ & $44512(11810)$ & $10842(2365)$ & $9541(1035)$ \\
\hline POA & $35523(12122)$ & $27132(5237)$ & $12899(2472)$ & $9953(959)$ \\
\hline LLOA & $35828(8999)$ & $40827(11537)$ & $10198(2552)$ & $9637(1104)$ \\
\hline LLIA & $34843(6904)$ & $35117(12003)$ & $11681(2235)$ & $9506(665)$ \\
\hline LONP & $47531(6811)$ & $45340(11793)$ & $12189(3216)$ & $13569(2206)$ \\
\hline RONP & $46565(7560)$ & $41029(8911)$ & $12803(3228)$ & $12987(2144)$ \\
\hline RLIA & $34805(7937)$ & $39635(9556)$ & $9928(3145)$ & $9992(971)$ \\
\hline RLOA & $34617(9562)$ & $41427(12338)$ & $9474(2657)$ & $10009(1096)$ \\
\hline $\begin{array}{l}\text { Anterior AF } \\
\text { averaged) }\end{array}$ & $36554(3806)$ & $42610(13888)$ & $8752(1589)$ & $9498(962)$ \\
\hline NP (averaged) & $44473(8168)$ & $39430(14619)$ & $11564(2955)$ & $13003(2036)$ \\
\hline Posterior AF \\
averaged)
\end{tabular}

Table IV. Glycosaminoglycan content per intervertebral disc region in relation to the histologic grade of disc degeneration

\begin{tabular}{|c|c|c|c|c|c|}
\hline $\begin{array}{l}\text { IVD REGION } \\
\text { [GAG G/MG DRY WEIGHT] }\end{array}$ & HDS I & HDS II & HDS III & HDS IV & HDS V \\
\hline $\mathrm{AOA}$ & $471(5.0)$ & $385(92)$ & $393(88)$ & $268(94)$ & $181(48)$ \\
\hline AIA & 805 (48) & $690(149)$ & $662(108)$ & $526(172)$ & $364(70)$ \\
\hline AONP & $864(20)$ & 802 (96) & $744(135)$ & $598(165)$ & 467 (90) \\
\hline NP & $851(28)$ & $754(129)$ & $697(122)$ & $550(141)$ & $424(84)$ \\
\hline PONP & $908(12)$ & $781(88)$ & $745(121)$ & 602 (158) & 485 (90) \\
\hline PIA & $866(5.0)$ & 794 (79) & 774 (98) & $665(147)$ & $529(95)$ \\
\hline POA & $609(13)$ & $481(122)$ & 447 (107) & 316 (89) & $236(92)$ \\
\hline LLOA & $543(98)$ & $529(78)$ & $480(113)$ & $350(104)$ & $225(97)$ \\
\hline LLIA & $898(5.0)$ & $730(122)$ & $716(121)$ & 517 (169) & $368(95)$ \\
\hline LONP & $879(81)$ & $767(163)$ & $742(132)$ & $548(142)$ & $435(96)$ \\
\hline RONP & $882(45)$ & $776(112)$ & $726(157)$ & 555 (159) & 418 (89) \\
\hline RLIA & $841(35)$ & $748(114)$ & $679(123)$ & $502(152)$ & $362(90)$ \\
\hline RLOA & $587(1.4)$ & $477(71)$ & $484(102)$ & $359(102)$ & 219 (99) \\
\hline Anterior AF (averaged) & $638(195)$ & $537(198)$ & $528(168)$ & $397(190)$ & $273(110)$ \\
\hline NP (averaged) & $877(39)$ & $776(116)$ & $731(132)$ & $570(152)$ & $446(91)$ \\
\hline Posterior AF (averaged) & $737(148)$ & $637(189)$ & $611(195)$ & $491(214)$ & $383(175)$ \\
\hline
\end{tabular}

Values in brackets represent standard deviations. 

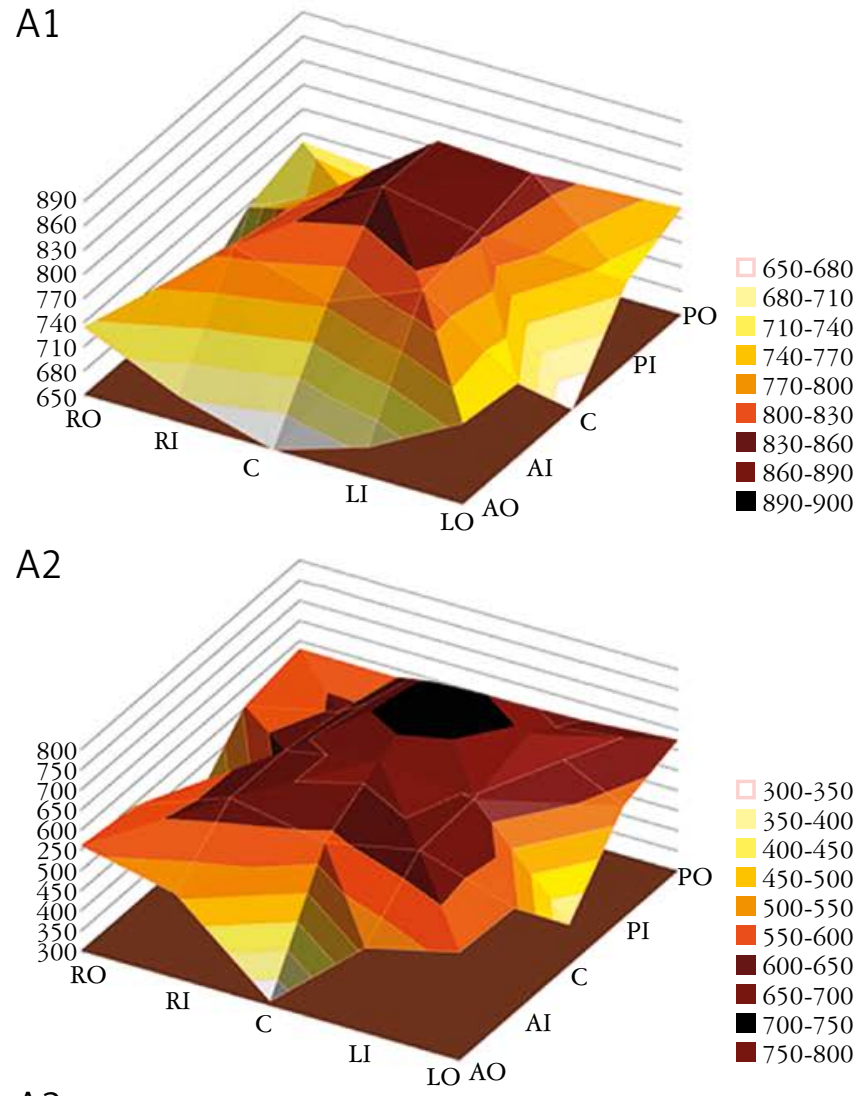

A3

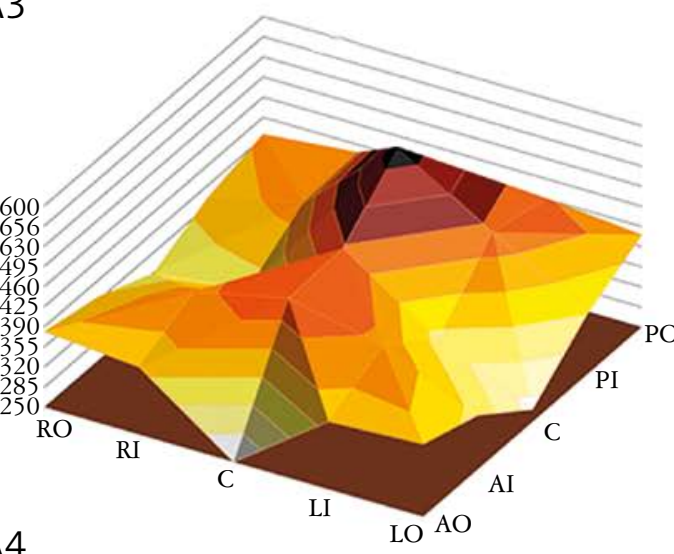

A4

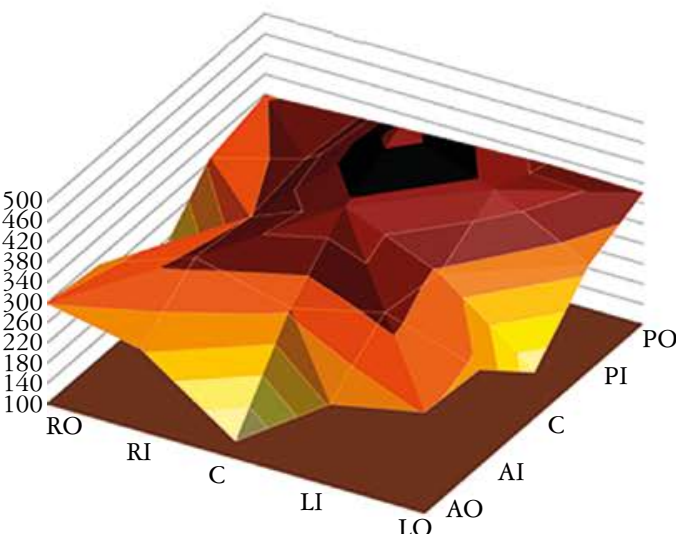

-300-350 $350-400$ $400-450$
$450-500$ - 500-550 - 550-600 - 600-650 - 650-700 - 700-750 - 750-800
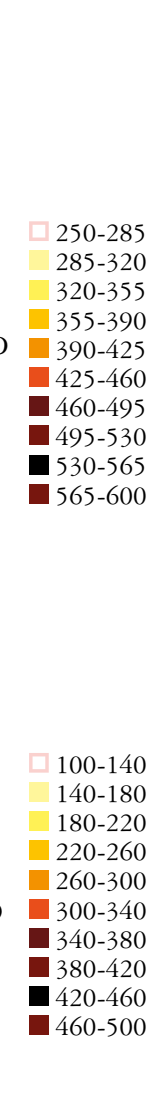

B1

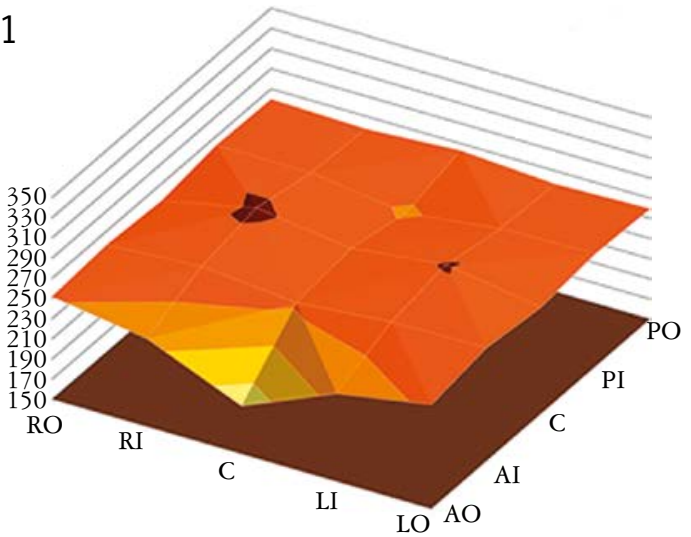

B2

$\square$ 150-170

170-190

190-210 $210-230$ - 250-270 $270-290$ - 290-310 - 310-330 - 330-350

B3
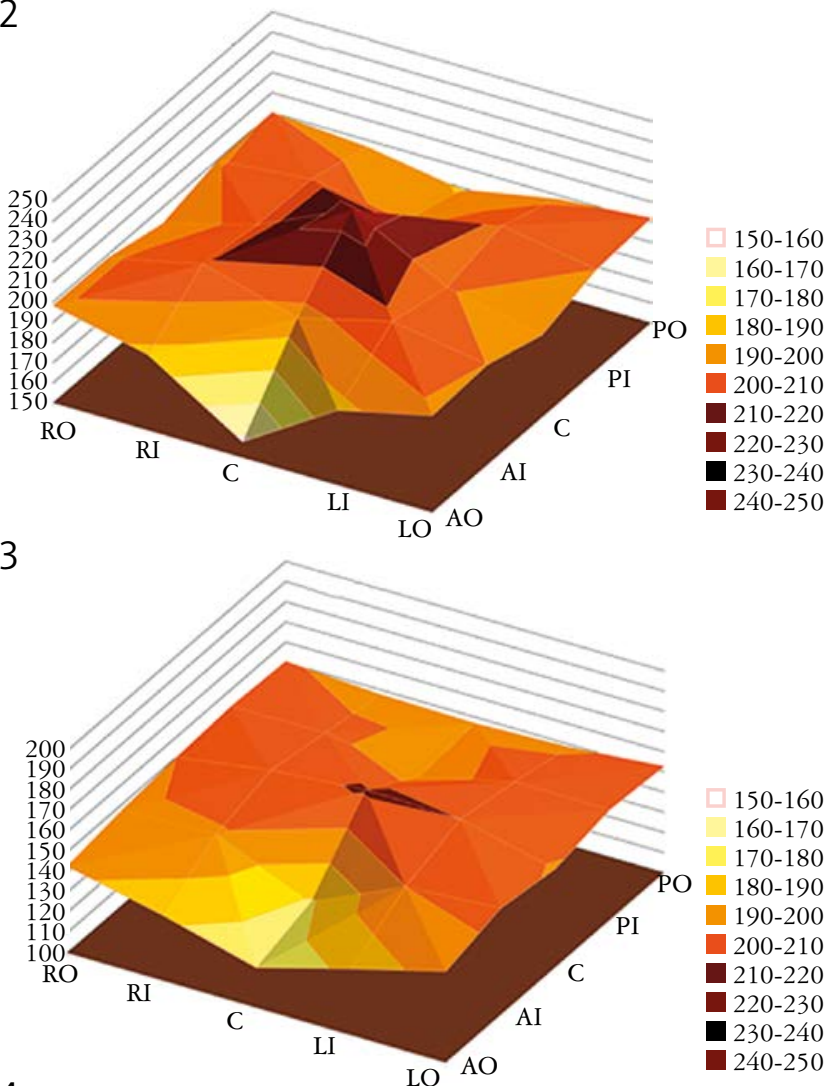

B4

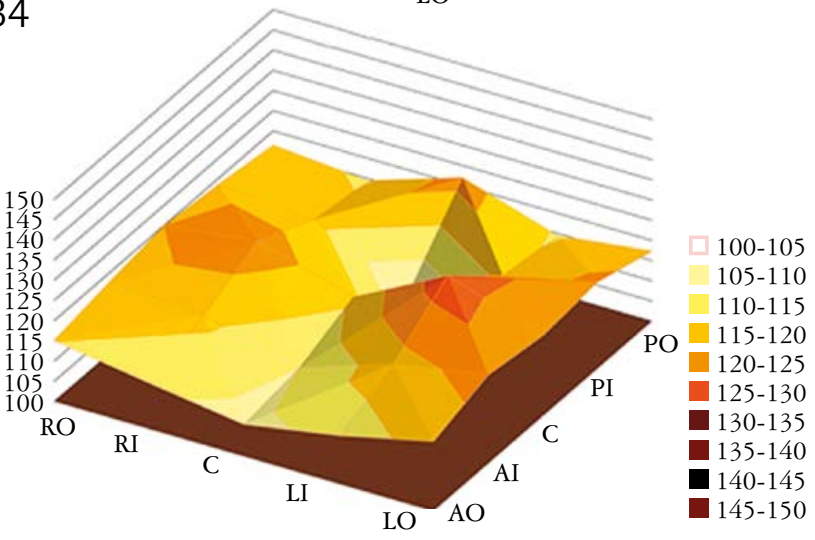

Please note the change in scale between different maps. Values are expressed as $\mu \mathrm{g}$ of GAG per $m g$ of dry tissue weight.

A1 - intervertebral disc (20-30 years old); B1 - endplate (20-30 years old); A2 - intervertebral disc (40-50 years old); B2 - endplate (40-50 years old);

A3 - intervertebral disc (60-70 years old); B3 - endplate (60-70 years old); A4 - intervertebral disc (80-90 years old); B5 - endplate (80-90 years old).

$C$ - center; $L I$ - left inner; $L O$ - left outer; $R I$ - right inner; $R O$ - right outer; $A O$ - anterior outer; $A I$ - anterior inner; $P I$ - posterior inner; PO - posterior outer.

Fig. 3. Three-dimensional maps of average glycosaminoglycan content in the intervertebral disc (A) and endplate (B) shown for different age groups 
Table V. Glycosaminoglycan content per endplate region in relation to histologic grade of disc degeneration

\begin{tabular}{llllll}
\hline $\begin{array}{l}\text { EP REGION } \\
\text { [GAG G/MG DRY WEIGHT }]\end{array}$ & HDS I & HDS II & HDS III & HDS IV & HDS V \\
\hline AOA & $178(37)$ & $182(16)$ & $168(31)$ & $153(25)$ & $123(25)$ \\
\hline AIA & $225(50)$ & $247(31)$ & $213(54)$ & $192(52)$ & $139(41)$ \\
\hline AONP & $242(31)$ & $260(29)$ & $241(46)$ & $222(43)$ & $151(44)$ \\
\hline NP & $252(36)$ & $254(23)$ & $240(50)$ & $224(36)$ & $158(47)$ \\
\hline PONP & $245(23)$ & $258(29)$ & $236(45)$ & $223(39)$ & $157(50)$ \\
\hline PIA & $220(62)$ & $244(36)$ & $221(44)$ & $191(45)$ & $137(38)$ \\
\hline POA & $252(42)$ & $251(37)$ & $210(56)$ & $204(46)$ & $156(38)$ \\
\hline LLOA & $238(39)$ & $251(34)$ & $214(46)$ & $195(46)$ & $148(35)$ \\
\hline LLIA & $246(51)$ & $266(28)$ & $227(50)$ & $206(52)$ & $162(43)$ \\
\hline LONP & $231(53)$ & $261(31)$ & $231(57)$ & $198(55)$ & $155(42)$ \\
\hline RONP & $237(52)$ & $263(33)$ & $224(53)$ & $201(51)$ & $153(37)$ \\
\hline RLIA & $250(42)$ & $271(26)$ & $227(49)$ & $210(49)$ & $155(40)$ \\
\hline RLOA & $232(48)$ & $242(27)$ & $218(55)$ & $195(49)$ & $153(39)$ \\
\hline Anterior AF (averaged) & $202(48)$ & $215(41)$ & $190(49)$ & $172(44)$ & $131(35)$ \\
\hline NP (averaged) & $242(38)$ & $259(27)$ & $234(49)$ & $214(46)$ & $155(44)$ \\
\hline Posterior AF (averaged) & $236(53)$ & $247(36)$ & $215(50)$ & $198(45)$ & $147(39)$ \\
\hline Vas bat & & & & \\
\hline
\end{tabular}

Values in brackets represent standard deviations.

age endplate GAG content for typical 20-30, 40-50, 60-70, and 80-90 years old are shown in Fig. 3B.

Endplate calcification strongly negatively correlated with cell density of the endplate $(\mathrm{r}=-0.58$ $(-0.68) ; \mathrm{p}<0.0001)$.

There were no significant differences between sexes in terms of endplate GAG content for all analyzed regions $(\mathrm{p}>0.05)$.

Figure 4 shows IVD GAG content variation in the axial direction in regard to HDS grade.

\section{Cell density and glycosaminoglycan content} correlations in the intervertebral disc and the endplates

Weak correlations existed between IVD cell density and cell density in corresponding EP regions $(\mathrm{r}=0.25$ $0.33 ; \mathrm{p}<0.01)$. This was not true only for the NP ( $\mathrm{p}>0.05)$.

Cell density in the IVD weakly correlated with IVD GAG content $(r=0.30-0.37 ; p>0.03)$ only in the NP regions. In the endplate no correlations were found between cell density and GAG content in the region underlying the NP. However, moderate correlations between GAG content and cell density were found in endplate regions underlying the right and left sides of the inner AF $(r=0.39-0.48$; $\mathrm{p}<0.01)$, and in the regions underlying the anterior $(\mathrm{r}=0.37 ; \mathrm{p}<0.02)$ and posterior outer $\mathrm{AF}(\mathrm{r}=0.39$; $\mathrm{p}<0.01)$.

\section{Discussion}

This study aimed at establishing cell density values as well as providing data on GAG content across different regions of the cervical IVD and its endplates. Recent years have seen a multitude of studies focusing on the analysis of changes in the extracellular matrix of the IVD during ageing $[4,5,7,13$, 14, 15, 16, 17, 18]. However, despite tremendous research efforts, we still lack knowledge regarding cell density and GAG content throughout the IVD. To the authors' best knowledge this is the first study to analyze cell density and GAG content in cervical IVDs and their endplates.

For our study we decided to use the well-validated Abercrombie method [22] of cell counting. Based on the previous experience of Liebscher et al. [8] using the Abercrombie method, we determined the "true" cell density in a three-dimensional space using 2-dimensional histological sections. As IVD cells have nuclei larger than $4 \mu \mathrm{m}$ (section thickness), the employed method prevented us from missing any nuclei during counting.

\section{Cell density in the intervertebral disc and the endplates}

Overall, taking into account the IVD, cell density was highest in the NP and gradually decreased outwards, with the anterior AF having significantly low- 


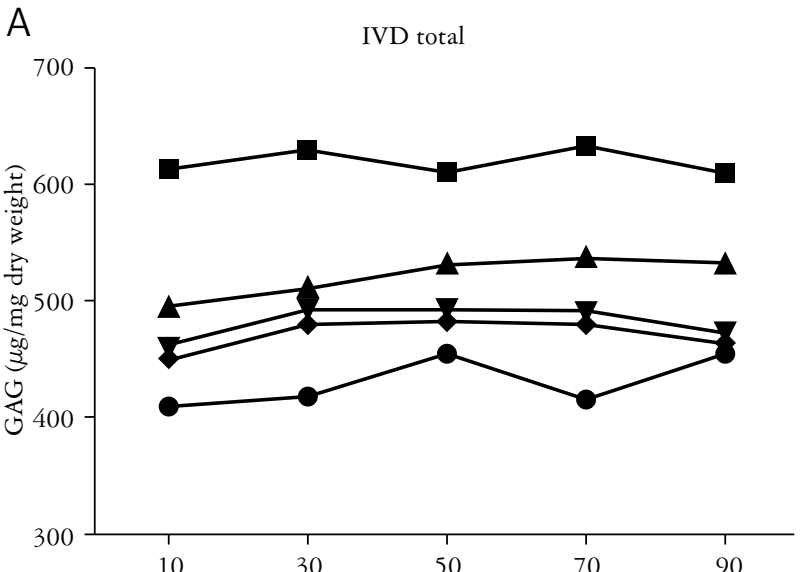

Axial direction (\% of distance cranial to caudal)

$\rightarrow$ Anterior AF $\rightarrow$ NP $\rightarrow$ - Posterior AF

$\checkmark$ Left AF $\multimap$ Right AF

C

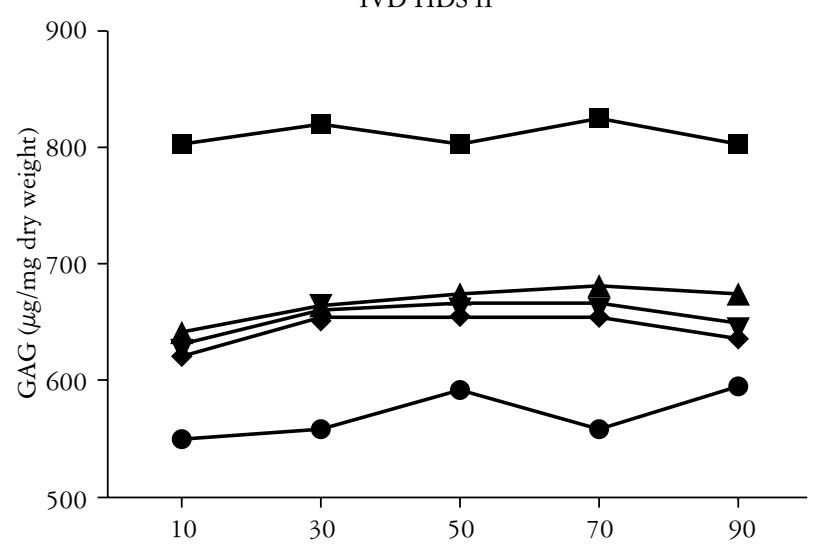

Axial direction (\% of distance cranial to caudal)

$\rightarrow$ Anterior AF $\rightarrow-\mathrm{NP} \rightarrow-$ Posterior AF

$\checkmark$ Left AF $\multimap$ Right AF

$\mathrm{E}$

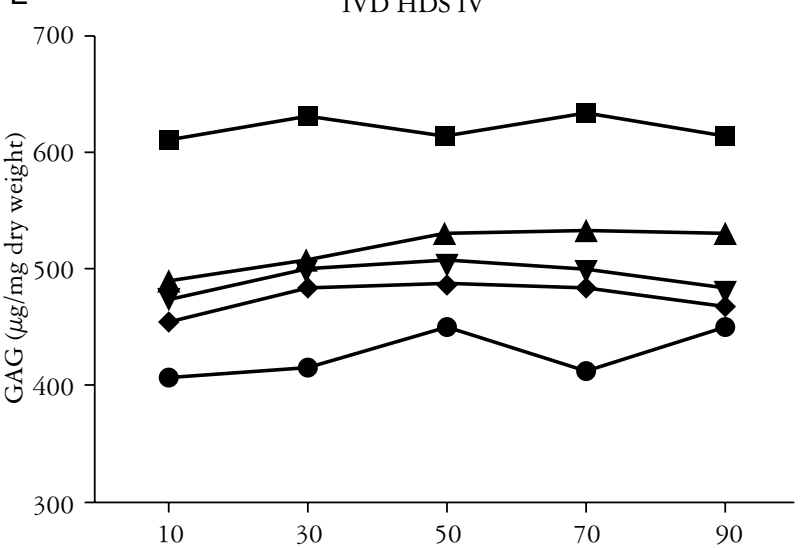

Axial direction (\% of distance cranial to caudal)

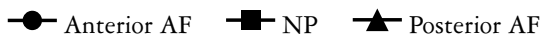

$\checkmark$ Left AF $\multimap$ Right AF
B IVD HDS I

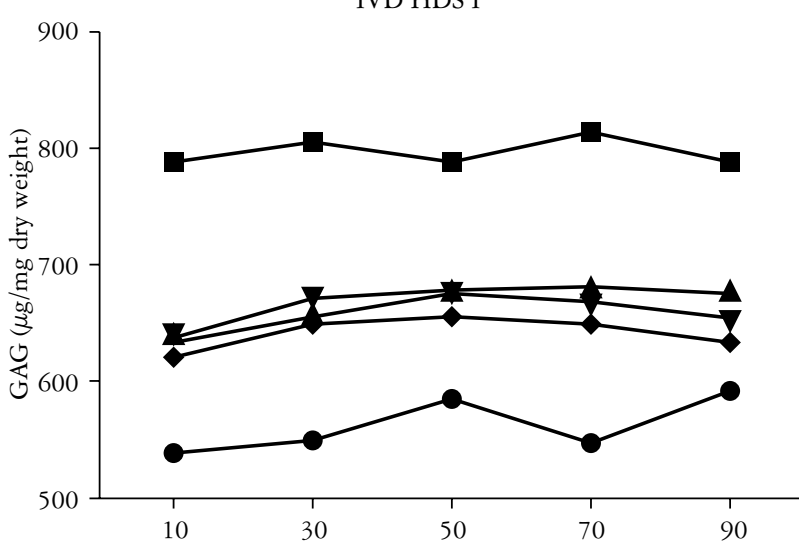

Axial direction (\% of distance cranial to caudal)

$\rightarrow$ Anterior AF $\rightarrow-\mathrm{NP} \quad \boldsymbol{t}$-Posterior AF

$\checkmark$ Left AF $\multimap$ Right AF

D IVD HDS III

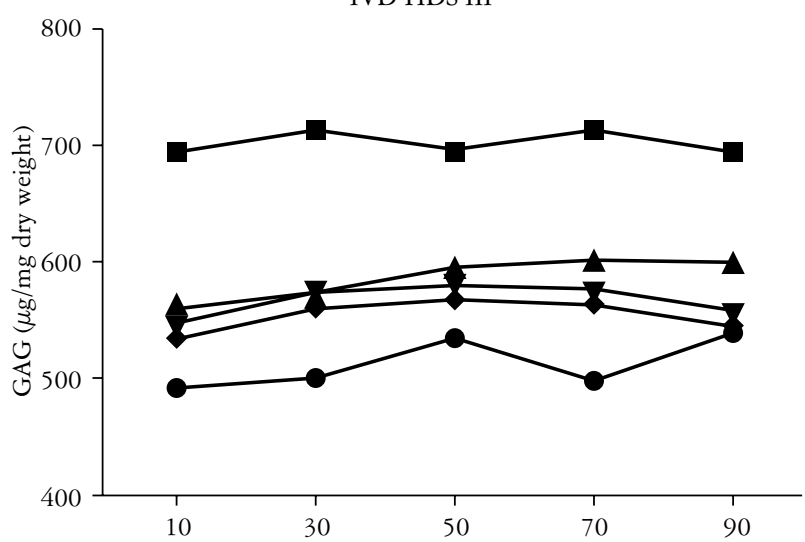

Axial direction (\% of distance cranial to caudal)

$\rightarrow$ Anterior AF $\rightarrow-\mathrm{NP} \quad \boldsymbol{t}$-Posterior AF

$\checkmark$ Left AF $\checkmark$ Right AF

F

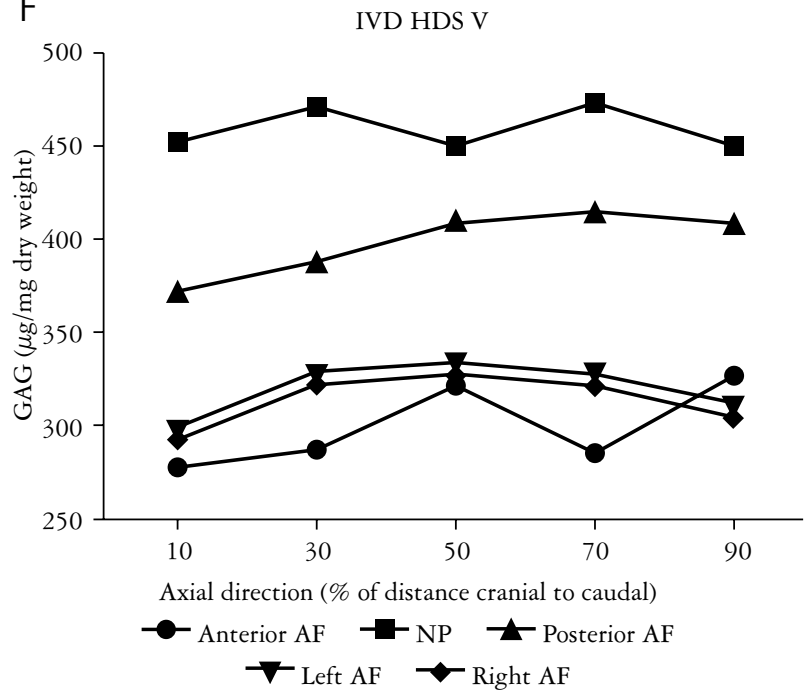

Please note the change in scale between different graphs.

IVD - intervertebral disc; GAG - glycosaminoglycan; HDS - bistological degeneration score; $A F$ - annulus fibrosus; NP - nucleus pulposus.

Fig. 4. Intervertebral disc glycosaminoglycan content variation in the axial direction in regard to histological degeneration score grade 
er cell density than the posterior AF. The differences in the anterior-posterior cell density might originate from the fact that nutrient supply to the posterior part of the IVD is generally thought to be better [24]. Nerlich et al. [25] also found that posterior vessels can be located deeper in the posterior AF in juvenile discs. In consequence, there is a small chance that some of these vessels persist, at least for a certain period of time, into adulthood, though generally this is considered unlikely [25]. There is still no agreement as to whether cell density decreases outwards from the NP [9] or remains constant throughout the IVD [8], as different studies present conflicting results. As this is the first study to analyze cervical IVDs, we support the theory that cell density is not homogeneous throughout the whole IVD. No significant side-related variations in cell density were noted. However, this might be explained by the fact that the IVD receives nutrients not only through the endplate but also from segmental artery branches that run along the vertebral bodies and allow nutrients to diffuse to the IVD from its sides [26].

With progressing degeneration, cell density in the IVD decreased. Age did not have a strong effect on cell density, which remained more or less constant with progressing age of the patients, with the exception of the NP and the anterior AF, where cell density decreased with ageing. This finding is in line with previous studies [8] which found that the most significant decrease of IVD cell density takes place between the $3^{\text {rd }}$ and $16^{\text {th }}$ year of life. This period witnesses dramatic changes occurring in the IVD, with the volume of the IVD increasing with a simultaneous decrease in blood supply (due to vascular regression) [25]. This results in a reduced diffusion rate [27] and therefore lower oxygen and glucose concentrations in the NP region, leading to a harsher cell environment [28]. This "vicious cycle" is further potentiated by endplate calcification, which impedes nutrient diffusion even more [21]. The above facts, together with age, which seemingly does not correlate with a decrease in cell density, might lead us to conclude that degenerative changes cause impairment of cell function rather than their death. This finding is in line with previously reported results $[8,16,29]$. It further elucidates the fact that even though in HDS grade IV IVDs a rise in cell density can be seen, these new cells remain "inactive" and do not produce extracellular matrix elements; thus they cannot contribute to IVD regeneration. Though the overall cell density does not significantly decrease with age, Fig. 2 shows that with age the spatial distribution of cells changes. Progressive loss of cells in the anterior and middle part (and not in the outer parts) of the IVD can be seen, further supporting the theory that nutrition is the key factor in preventing age- and degeneration-related IVD changes (as with endplate calcifi- cation the outer regions of the IVD tend to receive more nutrients).

Cranial and caudal endplates exhibited similar cell density and GAG content, as was also found by Rodriguez et al. [30]. The endplate presented similar cell density throughout all of its structure, in some cases "matching" IVD regions of low cell density with endplate areas of high cell density (e.g. Fig. 2.A1 and B1). As could be expected, increasing endplate calcification leads to a decrease in the number of cells. However, contrary to what we found in the IVD, in the endplate age significantly negatively correlated with endplate cell density. This finding might either stem from simple endplate calcification (which markedly progressed with age [31]) and physical destruction of cells or suggest that IVD cells are more resistant in nature, due to the "harsher" environment [28] that is present in the IVD when compared with the endplate.

\section{Glycosaminoglycans in the intervertebral discs and the endplates}

Proteoglycan molecules within the endplate matrix are necessary for the control of solute transport and maintenance of water content throughout the IVD. Depletion of proteoglycans from the endplate cartilage is associated with loss of proteoglycans from the NP [32]. The further consequence is that proteoglycan loss would ultimately lead to degeneration of the IVD [33].

Similarly to other studies [18] we found that the highest concentration of GAGs can be found in the region of the NP. Overall GAG content, in both the IVD and the endplates, followed cell density values. GAG production is considered a measure of IVD/ endplate cell activity [30]. Interestingly, sagittal and coronal variations in IVD GAG content were rather high when compared to previous studies [18]. However, this was only true for the IVD, while the endplate, regardless of donor age or IVD/endplate degeneration, had similar GAG content throughout all of its regions (Fig. 3B1-4). Axial variations in IVD GAG content were small and resembled those from lumbar IVDs [18].

Age and HDS score significantly negatively correlated with GAG content in both the IVD and the endplate. It is well recognized that GAG content decreases with degeneration [34]. Additionally, Rodriguez et al. [30] found that endplate porosity increases with age, while GAG content, as in our study, decreases. Collectively, the presented findings support the theory that endplate porosity increases with age, and that this may be an adaptive response to a reduction of nuclear swelling pressure. It is worth additionally underlining the fact that GAG content decreases with ageing, as this decrease might be suggestive of an age-related generalized decrease in cellular bio- 
chemical activity [15]. While it is hard to generalize the significance of this decrease, it is suggestive of a decreasing cellular response and extra-cellular matrix production that may have a significant role in how tissue injury is managed as a consequence of ageing.

Gender did not have an influence either on cell density or GAG content in both the IVD and the endplates. This finding is in line with previous studies $[8,30]$.

The strong points of this study include a large study group (one of the largest to date), a detailed histological analysis combined with a significant number of examined IVD and endplate regions in axial, coronal, and sagittal directions. To the authors' best knowledge this is the first study to assess cell density and GAG content in cervical IVDs and their endplates. However, this study has also one drawback. The youngest specimen in our study came from a 19-year-old person. This prevented us from analyzing how cell density and GAG content change during the years (3-16) when the IVD and the endplates undergo the greatest changes.

\section{Conclusions}

To conclude, this study introduces several detailed 3D maps of cervical IVD and cervical endplate cell density and GAG content. The most important prerequisite for successful IVD cell injection in cellbased tissue engineering approaches is a clear understanding of the actual cell numbers in normal and degenerated IVDs. Knowledge from this study may partially bridge the gap on IVD cell numbers in normal and degenerated discs.

Furthermore, the results from this study show that cervical IVDs and their endplates only slightly differ, in terms of cell density and GAG content, from their lumbar counterparts.

Additionally, this study provides new information characterizing GAG content distributions in the three primary directions in the IVD. This information may be helpful for future computer modeling of human IVD tissue. The presented data also reveal an overall age-related trend towards decreased IVD cellular metabolic activity as manifested by decreasing concentrations of GAGs.

Te authors declare no conflict of interest.

This study was funded by the National Science Center - Poland under grant number DEC-2012/07/N/ NZ5/00078, and by Jagiellonian University statutory funds for young scientists number K/DSC/002093. Krzysztof A. Tomaszewski received a scholarship to prepare his PhD thesis from the National Science Center - Poland under award number DEC-2013/08/T/NZ5/00020.

\section{References}

1. Roberts S, Evans H, Trivedi J, et al. Histology and pathology of the human intervertebral disc. J Bone Joint Surg Am 2006; 88: 10-14.

2. Niosi CA, Oxland TR. Degenerative mechanics of the lumbar spine. Spine J 2004; 4 (6 Suppl): 202S-208S.

3. Taylor JR, Twomey LT. Growth of human intervertebral discs and vertebral bodies. J Anat 1988; 120: 49-68.

4. Gruber HE, Hanley EN Jr. Ultrastructure of the human intervertebral disc during aging and degeneration: comparison of surgical and control specimens. Spine (Phila Pa 1976) 2002; 27: 798-805.

5. Nerlich AG, Schleicher ED, Boos N. 1997 Volvo award winner in basic science studies. Immunohistologic markers for age-related changes of human lumbar intervertebral discs. Spine (Phila Pa 1976) 1997; 22: 2781-2795.

6. Tomaszewski KA, Saganiak K, Gładysz T, Walocha JA. The biology behind the human intervertebral disc and its endplates. Folia Morphol (Warsz) 2015; 74: 157-168.

7. Boos N, Weissbach S, Rohrbach $\mathrm{H}$, et al. Classification of age-related changes in lumbar intervertebral discs: 2002 Volvo Award in basic science. Spine (Phila Pa 1976) 2002; 27: 26312644 .

8. Liebscher T, Haefeli M, Wuertz K, et al. Age-related variation in cell density of human lumbar intervertebral disc. Spine (Phila Pa 1976) 2011; 36: 153-159.

9. Hastreiter D, Ozuna RM, Spector M. Regional variations in certain cellular characteristics in human lumbar intervertebral discs, including the presence of alpha-smooth muscle actin. J Orthop Res 2001; 19: 597-604.

10. Meisel HJ, Siodla V, Ganey T, et al. Clinical experience in cell based therapeutics: disc chondrocyte transplantation a treatment for degenerated or damaged intervertebral disc. Biomol Eng 2007; 24: 5-21.

11. Gruber HE, Johnson TL, Leslie K, et al. Autologous intervertebral disc cell implantation: a model using Psammomys obesus, the sand rat. Spine 2002; 27: 1626-1633.

12. Revell PA, Damien E, Di Silvio L, et al. Tissue engineered intervertebral disc repair in the pig using injectable polymers. J Mater Sci Mater Med 2007; 18: 303-308.

13. Perie DS, Maclean JJ, Owen JP, et al. Correlating material properties with tissue composition in enzymatically digested bovine annulus fibrosus and nucleus pulposus tissue. Ann Biomed Eng 2006; 34: 769-777.

14. Cs-Szabo G, Ragasa-Sanjuan D, Turumella V. Changes in mRNA and protein levels of proteoglycans of the anulus fibrosus and nucleus pulposus during intervertebral disc degeneration. Spine (Phila Pa 1976) 2002; 27: 2212-2219.

15. Singh K, Masuda K, Thonar EJ, et al. Age-related changes in the extracellular matrix of nucleus pulposus and anulus fibrosus of human intervertebral disc. Spine (Phila Pa 1976) 2009; 34: 10-16.

16. Antoniou J, Steffen T, Nelson F, et al. The human lumbar intervertebral disc: evidence for changes in the biosynthesis and denaturation of the extracellular matrix with growth, maturation, ageing, and degeneration. J Clin Invest 1996; 98: 9961003.

17. Urban JPG, Maroudas A. The measurement of fixed charge density in the intervertebral disc. Biochim Biophys Acta 1979; 586: 166-178.

18. Iatridis JC, MacLean JJ, O'Brien M, et al. Measurements of proteoglycan and water content distribution in human lumbar intervertebral discs. Spine (Phila Pa 1976) 2007; 32: 14931497.

19. Le Maitre CL, Freemont AJ, Hoyland JA. The role of interleukin- 1 in the pathogenesis of human intervertebral disc degeneration. Arthritis Res Ther 2005; 7: R732-745. 
20. Thompson JP, Pearce RH, Schechter MT, et al. Preliminary evaluation of a scheme for grading the gross morphology of the human intervertebral disc. Spine 1990; 15: 411-415.

21. Tomaszewski KA, Adamek D, Pasternak A, et al. Degeneration and calcification of the cervical endplate is connected with a decreased expression of ANK, ENPP-1, OPN and TGF- $\beta 1$ in the intervertebral disc. Pol J Pathol 2014; 65: 204-211.

22. Abercrombie M. Estimation of nuclear population from microtome sections. Anat Rec 1946; 94: 239-247.

23. Mizia E, Tomaszewski KA, Lis GJ, et al. The use of computer-assisted image analysis in measuring the histological structure of the human median nerve. Folia Morphol (Warsz) 2012; 71: 82-85.

24. Crock HV, Yoshizawa H. The blood supply of the lumbar vertebral column. Clin Orthop Relat Res 1976; 115: 6-21.

25. Nerlich AG, Schaaf R, Walchli B, et al. Temporo-spatial distribution of blood vessels in human lumbar intervertebral discs. Eur Spine J 2007; 16: 547-555.

26. Raj PP. Intervertebral disc: anatomy-physiology-pathophysiology-treatment. Pain Pract 2008; 8: 18-44.

27. Rajasekaran S, Babu JN, Arun R, et al. ISSLS prize winner: a study of diffusion in human lumbar discs: a serial magnetic resonance imaging study documenting the influence of the endplate on diffusion in normal and degenerate discs. Spine (Phila Pa 1976) 2004; 29: 2654-2667.

28. Bibby SR, Urban JP. Effect of nutrient deprivation on the viability of intervertebral disc cells. Eur Spine J 2004; 13: 695-701.

29. Antoniou J, Goudsouzian NM, Heathfi eld TF, et al. The human lumbar endplate. Evidence of changes in biosynthesis and denaturation of the extracellular matrix with growth, maturation, aging, and degeneration. Spine (Phila Pa 1976) 1996; 21: 1153-1161.

30. Rodriguez AG, Slichter CK, Acosta FL, et al. Human disc nucleus properties and vertebral endplate permeability. Spine (Phila Pa 1976) 2011; 36: 512-520.

31. Tomaszewski KA, Adamek D, Konopka T, et al. Endplate calcification and cervical intervertebral disc degeneration: the role of endplate marrow contact channel occlusion. Folia Morphol (Warsz) 2015; 74: 84-92.

32. Roberts S, Urban JP, Evans H, et al. Transport properties of the human cartilage endplate in relation to its composition and calcification. Spine (Phila Pa 1976) 1996; 21: 415-420.

33. Pearce RH, Grimmer BJ, Adams ME. Degeneration and the chemical composition of the human intervertebral disc. J Orthop Res 1987; 5: 198-205.

34. Urban JP, McMullin JF. Swelling pressure of the lumbar intervertebral discs: influence of age, spinal level, composition, and degeneration. Spine (Phila Pa 1976) 1988; 13: 179-187.

\section{Address for correspondence}

Krzysztof A. Tomaszewski

Department of Anatomy

Jagiellonian University Medical College

Kopernika 12

31-034 Krakow, Poland

tel./fax +48124229511

e-mail:krtomaszewski@gmail.com 